\title{
Investigating the Central Executive in Adult Dyslexics: Evidence from Phonological and Visuo-Spatial Working Memory Performance.
}

\author{
James H. Smith-Spark, \\ Department of Psychology, Keynes College, University of Kent at Canterbury, Canterbury, \\ CT2 7NP, UK, \\ John E. Fisk, \\ School of Psychology, Liverpool John Moores University, 15-21 Webster Street, Liverpool, \\ L3 2ET, UK, \\ $\&$ \\ Angela J. Fawcett, Roderick I. Nicolson, \\ Department of Psychology, University of Sheffield, Sheffield, S10 2TN, UK.
}

\begin{abstract}
.
There is long-standing evidence for verbal working memory impairments in both children and adults with dyslexia. By contrast, spatial memory appears largely to be unimpaired. In an attempt to distinguish between phonological and central executive accounts of the impairments in working memory, a set of phonological and spatial working memory tasks was designed to investigate the key issues in working memory, task type, task demands (static, dynamic, and updating), and task complexity. Significant differences emerged between the dyslexic and non-dyslexic participants on the verbal working memory tasks employed in Experiment 1, thereby providing further evidence for continuing dyslexic impairments of working memory into adulthood. The nature of the deficits suggested a problem with the phonological loop, with there being little evidence to implicate an impairment of the central executive. Due to the difficulties associated with separating verbal working memory and phonological processing, however, performance was investigated in Experiment 2 using visuo-spatial measures of working memory. The results of the visuo-spatial tasks indicated no between-group differences in static spatial memory, requiring the short-term storage of simultaneously presented information. In almost all conditions there were no betweengroup differences in dynamic spatial memory that demands the recall of both location and order of stimuli presented sequentially. However, a significant impairment occurred on the dynamic task under high memory updating load, on which dyslexic adults showed non-phonological working memory deficits. In the absence of an explanation in terms of verbal recoding, this finding is interpreted in terms of a central executive or automaticity impairment in dyslexia.
\end{abstract}

\section{ACKNOWLEDGEMENTS.}

This work was supported by a Medical Research Council PhD studentship awarded to the first author. We are grateful to Professor Alan Baddeley, Dr. Jackie Andrade, Professor Keith Rayner, and two anonymous reviewers for comments made on earlier versions of this work. 


\section{INTRODUCTION.}

Developmental dyslexia is a condition that affects approximately $5 \%$ of the population in the western world (Badian, 1984). It is characterised by a difficulty with decoding the written word (e.g. Vellutino, 1979; Frith, 1985; Stanovich, 1988), although later research has suggested that problems may also occur outside the literacy domain (Nicolson \& Fawcett, 1990; Talcott, Hansen, WillisOwen, McKinnell, Richardson, \& Stein, 1998). Wolf and Bowers (1999) have integrated a number of findings to propose the 'double deficit' hypothesis, which posits that dyslexic children have core deficits not only in phonological skills but also in speed of processing.

McLoughlin, Fitzgibbon, and Young (1994) have identified impaired working memory as one of the major defining characteristics of the disorder and emphasise the impact of working memory deficits on individuals with dyslexia in everyday life. However, major laboratory tests of working memory have not yielded particularly strong results. A large corpus of evidence exists to indicate that dyslexics have deficits in short-term/working memory (e.g. Jorm, 1983; Cohen, Netley, \& Clarke, 1984; Ackerman \& Dykman, 1993; Brunswick, McCrory, Price, Frith, \& Frith, 1999; Pennington, Cardoso-Martins, Green, \& Lefly, 2001; Roodenrys \& Stokes, 2001; Wilson \& Lesaux, 2001; McDougall \& Donohoe, 2002; Plaza, Cohen, \& Chevrie-Muller, 2002), although the source of these problems, whether it be verbal working memory per se or phonological processing, remains unclear. This has led to some controversy over the amount of group variance attributable to deficits in phonological or memory processes (e.g. Gathercole, Willis, Emslie, \& Baddeley, 1991; Snowling, Chiat, \& Hulme, 1991; Gathercole, 1994).

\section{EXPERIMENT 1.}

Whilst there is a considerable body of evidence to indicate that dyslexics have deficits in working memory (e.g. Jorm, 1983; Miles, 1983), later research has suggested that performance on simple span tasks, such as word and digit span, is not so affected by the condition (Nicolson \& Fawcett, 1994; Wimmer, 1993). Indeed, it has been suggested that memory span differences between dyslexics and controls can be accounted for in terms of phonological processes, such as slow articulation rate (Nicolson, Fawcett, \& Baddeley, 1994; Avons \& Hanna, 1995; Hulme, Roodenrys, Brown, \& Mercer, 1995; McDougall \& Donohoe, 2002).

Three phonological working memory tasks were administered in Experiment 1 to examine, as far as possible, the relative contribution of the phonological loop and the central executive (e.g., Baddeley, 1986) to the verbal working memory impairments apparent in both children and adults with dyslexia. The working memory model (e.g., Baddeley, 1986) argues for a modality-free central executive controlling at least two active slave systems, the phonological loop and the visuo-spatial sketchpad, which are concerned with the storage and processing of information from different sensory modalities. The phonological loop holds language-based material, whilst the visuo-spatial sketchpad is concerned with the storage of visual and spatial information. The tasks described in Experiment 1 consisted of measures of simple short-term memory (digit and word span), together with a test assumed to involve the central executive component of Baddeley's working memory model, namely a letter updating task similar to that of Morris and Jones (1990). This task involves the presentation of lists of $6,8,10$, and 12 consonants, with the participants being requested to recall the six most recent items. Successful task performance required the participants to hold the 
first six items in memory and then, if there were more than six items in a list, to update the contents of memory by dropping the least recent item and adding the new item to the string. The participants needed to repeat the updating process for each additional item in a list over six items. The lists were presented visually at a rate of one item per second. This procedure required subjects to make between 0 and 6 updates and is argued to utilise the central executive. The participants were then asked to recall the last six items in the order that they were presented. The articulatory rehearsal function of the phonological loop is required by the task's serial recall component. Morris and Jones were able to disrupt serial order recall using the articulatory suppression and the unattended speech effects, whilst the memory updating aspect was not affected by the phonological loop or disruption to it. This result demonstrates that updating is independent of memory load. Updating tasks appear to be more like the demands made on working memory in day-to-day life than do tests of serial order memory. Seldom does the individual have the luxury of being able to maintain just one string of information in working memory; more often than not, he or she must "juggle" various pieces of information in working memory. Deficits in the accuracy of verbal working memory updating in dyslexic children have been reported by Ackerman and Dykman (1993), but the demands of their running memory task were not as great as those of the task described in this paper.

\section{METHOD.}

\section{Participants.}

Two groups of university students took part in the experiment. One group consisted of 12 dyslexics (4 female, 8 male) obtained from a pool of dyslexic individuals diagnosed by researchers at the University of Sheffield, using Nicolson and Fawcett's (1997) Adult Dyslexia Diagnostic Test. This adult dyslexia diagnosis tool provides an Adult Dyslexia Index (ADI) score for an individual. Four positive indicators of dyslexia are used to obtain the ADI score, namely the full WAIS-R (Wechsler, 1986a), WORD spelling (Wechsler Objective Reading Dimensions; Wechsler, 1986b), speed and accuracy of reading of a nonsense passage known to identify deficits even in compensated dyslexics (Finucci, Guthrie, Childs, Abbey, \& Childs, 1976; Brachacki, Fawcett, \& Nicolson, 1994), and a previous diagnosis of dyslexia. Performance on each of the four indicators provides a score of 0 , 0.5, or 1. Nicolson and Fawcett (1997) describe the method of determining the cut-off scores on each of the indicators in depth. Composite scores on the tests provide an ADI score ranging from 0 (non-dyslexic) to 4 (dyslexic). Scores of 3 or more provide strong evidence for dyslexia, 2.5 represents good evidence for the condition, scores of 1.5 to 2 are taken as cases of "borderline" dyslexia, whilst 1 and below are interpreted as providing no evidence of dyslexia. A mean ADI score of $3.04(\mathrm{SD}=0.70)$ and a mean IQ of $109.33(\mathrm{SD}=10.36)$ were obtained for the dyslexic group in the present study. The performance of the individual dyslexic participants on the ADI measures is shown in Appendix I.

The control group of 16 non-dyslexics ( 8 female, 8 male) was obtained through a universityrun student employment agency. When questioned, none of the control participants reported that they were dyslexic and all stated that they had no problems with reading or spelling (a point borne out by their written work during testing; Smith-Spark, 2000). Self-reports of being non-dyslexic 
have been found to be accurate by Nicolson and Fawcett (1997) in a study of 150 students, none of whom showed any evidence of dyslexia ${ }^{1}$.

On average, the dyslexic group was slightly older than the control group (mean $=25.42$ years, 20.84 years; $\mathrm{SD}=5.04,1.61$, respectively). The number of years spent in formal education was similar for the dyslexic (mean $=15.50$ years, $\mathrm{SD}=1.51)$ and control groups $($ mean $=15.63$ years; $\mathrm{SD}=1.41)$.

\section{Materials.}

An Apple MacIntosh IIci computer was used to present the word and digit span tasks. The test items were recorded using SoundEdit Pro and transferred to Hypercard using the Hypersound Toolkit. Pen and paper were supplied. The letter updating experiment was presented on an IBM-compatible Viglen 4DX33 PC. The participants were provided with a pen and an answer booklet.

\section{Design.}

The order of presentation of the tests was fully counterbalanced.

The Simple Verbal Span Measures: There were two tests of simple span, digit span and word span. The participants were presented with auditory lists (sets) of words and digits, which had been recorded using SoundEdit Pro and transferred to Hypercard using the Hypersound Toolkit. The digits and words were played back at a rate of one word per second. A short practice session preceded the two tests. The word lists for each span level of the task were the same as those used by Fisk and Warr (1996). The digits 0-9 inclusive were used in this task. Initially, the sets consisted of 2 stimuli. Three such sets were presented. If the participant recalled two or more of the lists successfully in serial order, then he or she was asked to recall lists containing three stimuli. The list size increased until the point was reached where the participant was unable to recall correctly at least two of the three stimulus sets. At this point the test was terminated. Simple memory span was calculated as being equal to the largest list size at which the participant remembered more than one of the three lists correctly.

The Letter Updating Task: The participants were requested to recall in serial order the last six consonants of a sequence shown one at a time on a VDU. The number of letters in any one sequence varied from $6,8,10$, to 12 . The participants were not warned of the number of consonants that would be presented on any given trial (i.e. the number of updating operations required was unknown). The sequences were presented in six blocks of four trials with one sequence at each level of the task being shown in a random order. Thus, in total, the task consisted of twenty-four letter sequences. The test was self-paced, with the next set of letters appearing only after the participant hit a key to continue. The consonants were selected at random, subject to the requirement that no letter appeared in the same list more than once. The timings of the presentations were based on those used by Morris and Jones (1990).

\footnotetext{
${ }^{1}$ Ideally the groups would have been matched for IQ, but due to an error in the original design, the controls were not given a short-form IQ test.
} 
Procedure.

The Simple Verbal Span Measures: The participants were asked to listen to lists of words or digits and were requested to repeat them back in the same order at the end of the presentation. The experimenter recorded the participant's responses as they were spoken and then compared them to the correct answers displayed on the screen. Errors were recorded for later analysis.

The Letter Updating Task: The participants were told that they would be presented with a number of letters. As each letter appeared on the screen, they were asked to speak it aloud and to try to remember it. At the end of each set they were requested to write down in the answer book the last six letters only in the order in which they appeared. It was emphasised that the number of letters in each set would vary but they were always only to write down the last six to be presented. After the presentation of the letters, the participants were asked to turn to a new page in the answer booklet and write down the letters in the order in which they appeared. Once they had done this, they pressed a key to start the next trial.

\section{RESULTS.}

\section{The Simple Verbal Span Measures.}

The span levels of the dyslexic and control groups differed significantly on both the digit span task, $t(24)^{2}=3.50, p=.002$, and the word span test, $t(26)=3.24, p=.004$, with the dyslexic group scoring at a lower level on both measures. On the digit span task, the dyslexic group had a mean span level of $5.25(\mathrm{SD}=0.75)$ compared to the control group's mean span level of $6.50(\mathrm{SD}=1.02)$. In the case of the word span task, the mean span level of the dyslexic group was $4.17(\mathrm{SD}=0.58)$, whilst that of the control group was $4.93(\mathrm{SD}=0.62)$.

\section{The Letter Updating Task.}

A repeated measures MANOVA was performed on the data of the letter updating task. This uncovered a significant group effect, $F(1,26)=10.95, p=0.003$, with the dyslexic group performing significantly worse overall on the test. Table 1 shows the mean scores and univariate $F$ test results for the four conditions of the letter updating task. A significant main effect of condition was also found, $F(3,78)=4.15, p=0.009$, with recall declining with the presentation of an increasing number of letters. There was no significant group $\mathrm{x}$ condition interaction, $F(3,78)=$ $1.65, p=0.186$.

Serial position had a significant effect on recall, $F(5,130)=141.44, p<0.001$, with letters that were presented later on in the sequence being recalled significantly better than those presented earlier in the trial. There was no significant group $\mathrm{x}$ serial position interaction, $F(5,130)=1.33, p=$ 0.256 . However, a significant interaction between condition and serial position was found, $F$ ( 15 , $390)=18.66, p<0.001$, with the difference appearing to centre on the least recently presented letters between the 6 letter condition and the higher 3 levels of complexity. There was no evidence

\footnotetext{
${ }^{2}$ The data for two control participants are missing from this analysis.
} 
of a significant three-way interaction between group, condition, and serial position, $F<1$. Figure 1 shows the serial position data for the two groups on each condition of the letter updating task.

Table 1: Mean recall scores (with standard deviations in parentheses) for the letter updating task. Multivariate F-test results are also shown.

\begin{tabular}{|c|c|c|c|}
\hline Condition & Mean Correct Recall & $\boldsymbol{F}$ & Sig. \\
\hline 6 Letters Presented & $\begin{array}{c}\text { Controls }=24.06 \\
\text { Dyslexics }=17.67\end{array}$ & 9.031 & $p=.006$ \\
\hline 8 Letters Presented & $\begin{array}{c}\text { Controls }=21.94 \\
\text { Dyslexics }=17.17\end{array}$ & 9.127 & $p=.004$ \\
\hline 10 Letters Presented & $\begin{array}{c}\text { Controls }=21.38 \\
\text { Dyslexics }=16.75\end{array}$ & 10.143 & $p=.094$ \\
\hline
\end{tabular}

Figure 1: Graphs showing serial position data for both groups on each level of the letter updating task.

6 Letters.

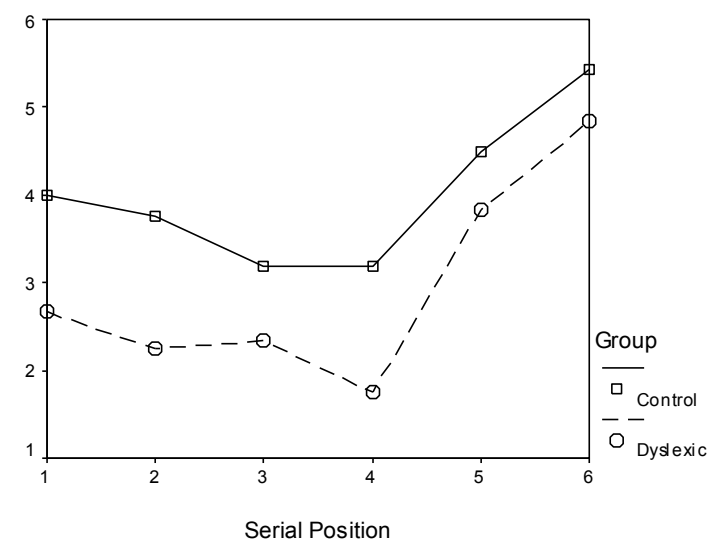

8 Letters.

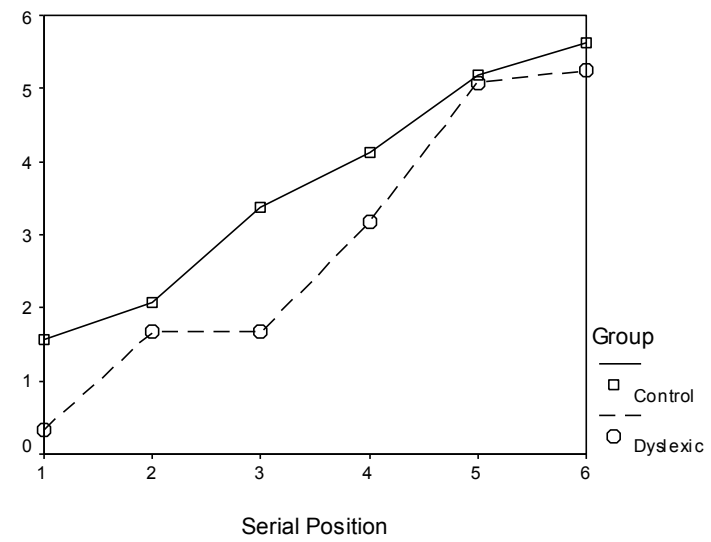

10 Letters.

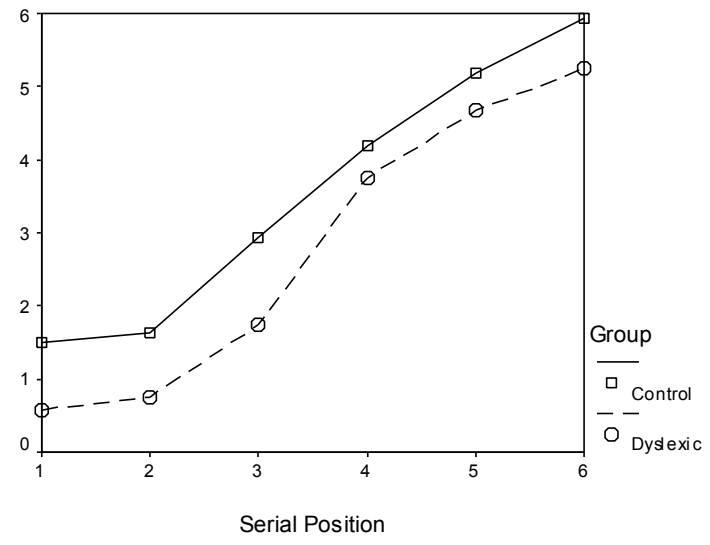

12 Letters.

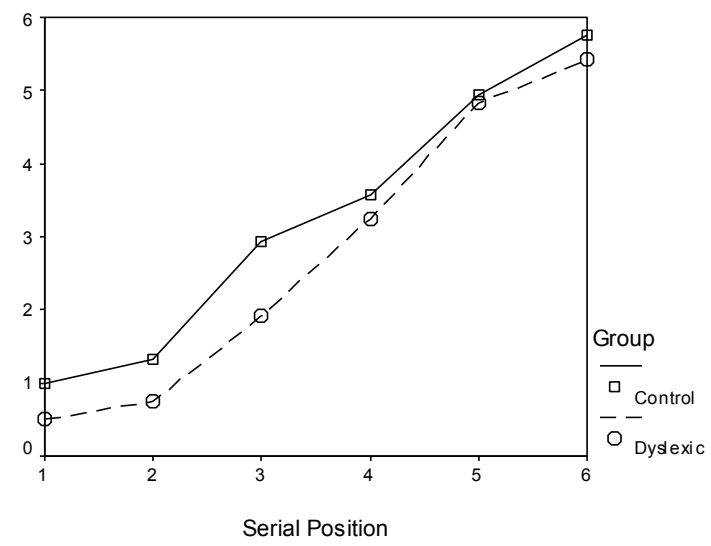




\section{DISCUSSION.}

Consistent with previous studies of verbal working memory in dyslexia (e.g., Jorm, 1983; Miles, 1983; Cohen, Netley, \& Clarke, 1984; Ackerman \& Dykman, 1993), significant dyslexic impairments were uncovered on both the digit and word span tasks. As expected, the dyslexics also proved to be significantly worse overall on the letter updating task, but no significant group $\mathrm{x}$ condition interaction was evident. Table 1 reveals that the dyslexic group was relatively unaffected by list length while the control group exhibited the usual drop in performance at the longer list lengths. Thus, there appears to be little evidence of executive involvement in the task among the dyslexic group. The particularly poor performance at the early serial positions implicates a failure of the articulatory control process. If this were the case, then there would be little or nothing for the executive to do, since recall of the early serial positions is already compromised by the impaired functioning of the phonological loop. Indeed, the overall pattern of performance of the dyslexic group is suggestive of the operation of qualitatively different processes (e.g., a 'recency'-based mechanism; Baddeley and Hitch, 1993). If this were the case, then the phonological basis of the letter updating task renders it unsuitable to test for central executive impairment.

The pattern of the findings on the letter updating task seems, thus, to argue for phonological impairment and less for the involvement of the central executive. However, as Snowling, Chiat, and Hulme (1991) state, it is extremely difficult, even in the most tightly controlled laboratory experiment, to divorce phonological memory entirely from other phonological processes. An obvious, yet under-examined, way to investigate working memory in dyslexia without the confounding effects of phonological processing is to consider performance on a task that is visuospatial in nature, with little or no phonological component. Since Vellutino (1979) concluded from a number of experiments carried out in his laboratory that dyslexics were unimpaired on visuo-spatial tasks, performance in this modality has been largely ignored by dyslexia researchers. It is plausible, however, that the visuo-spatial tasks used previously were not sufficiently demanding to elicit significant differences. Recent work by Winner, von Karolyi, Malinsky, French, Seliger, Ross, and Weber (2001) tends to support such an argument, since they found that their dyslexic participants performed worse than the controls on a number of visuo-spatial tasks. Tasks designed to investigate visuo-spatial working memory performance may prove to be a fruitful means of divorcing phonological loop processes from those of the central executive. To this end, Experiment 2 will explore visuo-spatial working memory using a battery of tasks designed to tease out whatever relationship there may be between the central executive, visuo-spatial sketchpad, and dyslexia.

\section{EXPERIMENT 2.}

Pickering and colleagues (Pickering, 2001; Pickering, Gathercole, Hall, \& Lloyd, 2001) have argued that the separable 'visual cache' and 'inner scribe' subsystems in visuo-spatial working memory (e.g. Logie \& Pearson, 1997) may be sensitive to the static and dynamic features of a visuospatial stimulus. Using the terminology of Pickering et al., 'static' memory tasks require the shortterm storage of simultaneously presented information within visuo-spatial working memory. On the other hand, 'dynamic' tasks involve the recall of both location and order of stimuli presented sequentially. The updating conditions, with varying memory load, demand that the individual update the contents of working memory as new information enters the system (e.g. Morris \& Jones, 1990) and, thus, require both storage and some form of simultaneous processing, drawing upon the central executive. 
Whilst the static / dynamic memory distinction has been upheld in visuo-spatial working memory (e.g. Bruyer \& Scailquin, 1998; Pickering, Gathercole et al., 2001; Vecchi \& Cornoldi, 1999), extant studies of the functioning of this component in dyslexia have not investigated the difference in any great depth. Some recent studies involving visuo-spatial working memory have uncovered dyslexic impairments. For example, Swanson (1999), using a matrix task with a processing component, found there to be a significant difference between reading-disabled children and controls in executive processing independent of phonological skill. Olson and Datta (2002) found poorer performance by the dyslexic than the non-dyslexic children on a visual matching task, which required both visual processing and short-term memory for complex patterns. The magnitude of the effect was not so great as on their phonological measures, but was evident nonetheless.

Experiment 2 will determine what effects there are on the performance of dyslexic participants when the static-dynamic distinction is made explicit. For the static condition of the experiment, the spatial memory task of Salthouse, Kausler, and Saults (1988a, 1988b) was employed. This required participants to recall the location of seven cells presented simultaneously in a 5x5 matrix (see Figure 2). In the dynamic condition of the present study, four cells were highlighted sequentially within a 5x5 matrix (see Figure 3 ) and participants had to recall the locations in which they appeared in the correct order. The number of cells to be highlighted on any one trial was unknown to the participant in the updating condition and varied between 4 and 10 . The participant was requested to recall in serial order the positions of the last four cells to be marked in the sequence. Thus, whilst both conditions are essentially dynamic in nature (since they involve the presentation of a spatial movement sequence), they are distinguished by the presence (the 'updating' condition) or absence (the 'dynamic' condition) of uncertainty in the list length to be presented. Fisk and Sharp (1999) have selectively impaired performance on the updating component of the spatial task using a concurrent random letter generation task, thereby making an explicit link between the central executive and the ability to update memory on the task similar to Morris and Jones' (1990) separation of the serial order memory and updating components of the letter updating task described in Experiment 1. By comparing performance under this condition with recall under a concurrent tapping requirement, Fisk and Sharp were able to determine that disruption was not the result of increased attentional demands.

The findings of Experiment 2 should have a significant bearing on a number of important theoretical issues. Since, according to the phonological deficit hypothesis (Vellutino, 1979), verbal processes are responsible for most, if not all, dyslexic working memory impairments ${ }^{3}$, the performance of participants with dyslexia on a visuo-spatial (and, thus, overtly non-phonological) working memory task would not be expected to differ from that of a control group of non-dyslexics. Furthermore, a dyslexic impairment on the updating component of the task, which according to Morris and Jones (1990) is not dependent on the phonological system, would equally not be expected. Thus, the task should make a useful distinction between theories of dyslexia that view the deficit as solely (or predominantly) a phonologically-based deficit (Vellutino, 1979; Snowling, 1987; Stanovich, 1988) and those that view the condition from a wider perspective (e.g. Nicolson \& Fawcett, 1990; Nicolson, Fawcett, \& Dean, 1995, 2001; Wolf \& Bowers, 1999). Work by Swanson and colleagues (Swanson, 1993; Swanson, 1999; Swanson and Sachse-Lee, 2001) has argued for a domain-general deficit in working memory, with problems in executive processing skill. Swanson and Sachse-Lee (2001) found that the performance of the reading-disabled and control groups was equivalent on verbal and visuo-spatial tasks once executive ability was taken into account.

\footnotetext{
${ }^{3}$ A point supported also by the data reported in Experiment 1.
} 


\section{METHOD.}

Participants.

See Experiment 1.

Materials.

The experiment was presented on an IBM-compatible Viglen 4DX33 PC. The display consisted of a $5 \times 5$ matrix. Figure 2 shows an example of a trial from the static condition of the experiment.

Figure 2: An example of the $5 \times 5$ matrix used in the pattern memory task, with ' $X$ 's marking the seven cells to be remembered.

\begin{tabular}{|c|c|c|c|}
\hline 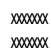 & $\underbrace{200000 x}$ & & \\
\hline & $x_{0}$ & & $\begin{array}{l}x \\
x=0000 x \\
x=000 x\end{array}$ \\
\hline 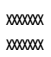 & & 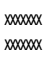 & \\
\hline$\frac{1}{20000 x}$ & & & \\
\hline
\end{tabular}

In the case of the dynamic and updating conditions of the task, cells were highlighted sequentially with rows of Xs. A sequence in which 4 cells are presented is shown in Figure 3.

Figure 3: A sequence of 4 cells highlighted sequentially with rows of Xs.
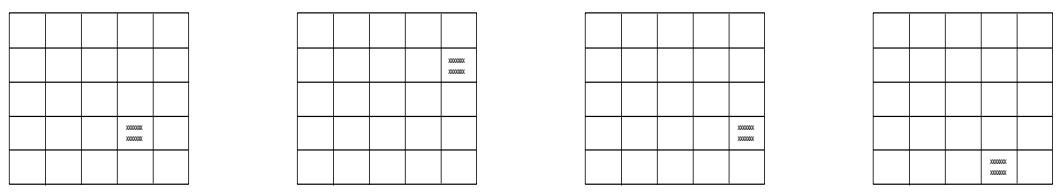

Participants were given a pen and two answer booklets (one for the static condition and one for the updating task), with a single $5 \times 5$ matrix printed on each page.

Design and Procedure.

The Spatial Memory Task (Salthouse et al., 1988a, 1988b): This task requires the recall of seven spatial locations marked simultaneously with Xs within a $5 \times 5$ matrix. The matrix was displayed for three seconds. The participants were told that they would be presented with a pattern and were asked to remember the location of all the cells that contained crosses. The participants were requested to use a pen to mark the position of the highlighted cells in an answer book. Once they had done this, they hit a key on the keyboard to view the next matrix. The same procedure was followed for the 6 trials of the task. The total number of cells correctly recalled on each trial was recorded. If participants placed more than 7 cells on any one trial, then one point was subtracted from their score on that trial for each cell marked in excess of 7.

Spatial Memory - Dynamic and Updating Conditions: The remaining two tasks followed the same overall design as employed by Fisk and Sharp (1999), with there being dynamic and updating conditions to the experiment. The dynamic condition was presented separately to the updating task. 
The order of presentation of the tests was fully counter-balanced. Accuracy data for each serial order position was recorded. The dynamic condition required serial order recall of the position of four cells highlighted sequentially within a $5 \times 5$ matrix. Participants were told that only four positions would be presented on each trial. In the updating condition, the participant was requested to recall in serial order the positions of the last four cells in the sequence. The number of cells highlighted on any one updating trial was unknown to the participant and varied between $4,6,8$, and 10 . In line with the letter updating task of Morris and Jones (1990) and that reported in Experiment 1, each cell in the sequence was highlighted for 1 second. Therefore, when the fifth cell was marked, updating of the contents of working memory had to occur. Older items had to be removed and the list reordered according to incoming information. The participant had to re-label the cells, dropping the first cell to be presented from memory and re-allocating ordinal tags to the cells that follow it. The procedure required subjects to make between 0 and 6 updates. At the end of each trial, participants were requested to mark down in the answer book the highlighted cells in the order in which they appeared, marking the appropriate cells from 1 (the earliest presented) to 4 (the most recently presented). There was no time limit to recall. Participants were able to control the onset of the next sequence of cell positions by hitting any key on the keyboard. In order to avoid any interference effects, they were requested to turn to the next page of the answer booklet before continuing. Six trials were presented at each complexity level of the task. The four stimulus complexity types were presented in a semi-random fashion. The order of presentation was the same for all participants.

\section{RESULTS.}

\section{$\underline{\text { 1. Spatial Memory Task. }}$}

No significant group difference was found on the static spatial memory task, $t(26)=1.39, p=$ 0.423 . There was a mean group difference of 2.25 in the number of cells recalled correctly, with the dyslexics recalling slightly fewer positions correctly (mean $=32.75, \mathrm{SD}=4.88)$ than the controls $($ mean $=35.00, \mathrm{SD}=3.67)$.

\section{Dynamic Versus Updating Conditions.}

In order to ensure that updating was occurring on the main task, performance on the simplest level of the updating condition (with four cells being highlighted) was compared with recall on the dynamic condition. A repeated measures MANOVA showed no significant effect of group on recall, $F(1,26)=1.82, p=0.189$. There was a significant effect of condition, $F(1,26)=23.36, p<0.001$, with participants recalling significantly more cells correctly under the dynamic condition.

The group $\mathrm{x}$ condition interaction was just short of significance, $F(1,26)=3.47, p=0.07$. It would seem that the dyslexics were rather more affected by the introduction of uncertainty than were the controls. Serial position had a significant effect on recall, $F(3,78)=5.12, p<0.01$, with the two most recent items being, in general, recalled more successfully. There was no significant interaction between group and serial position, $F<1$. However, a significant interaction did emerge between condition and position, $F(3,78)=7.90, p<0.001$. Recall remained relatively stable over the four items on the static condition but was lower for the first two items of the updating condition. There was no evidence of a significant group $\mathrm{x}$ condition $\mathrm{x}$ position interaction, $F<1$.

\section{Memory Under Updating Conditions.}

A repeated measures MANOVA was performed on the updating conditions of the pattern memory updating task, with group as the between-subjects factor and number of updates (with four levels) being the within-subjects factor. There proved to be no significant overall difference in recall between the controls and dyslexics, $F(1,26)=1.44, p=0.241$. However, the number of updates required had a significant effect on performance, $F(3,78)=17.52, p<0.001$. An increased updating memory load led to lower recall scores for both groups. There was a significant interaction 
between group and updating, $F(3,78)=3.29, p<0.05$, with the dyslexic participants scoring significantly lower than the controls when the maximum number of updates were required. Overall group mean recall scores for all of the dynamic and updating conditions of the visuo-spatial working memory task are shown in Table 2, together with multivariate F-test results.

Table 2: Mean recall scores (with standard deviations in parentheses) for both the dynamic and updating conditions of the pattern memory task. Multivariate F-test results are also shown.

\begin{tabular}{|c|c|c|c|}
\hline Condition & Mean Correct Recall & $\boldsymbol{F}$ & Sig. \\
\hline $\begin{array}{l}\text { 4 Cells Highlighted } \\
\text { Dynamic Condition }\end{array}$ & $\begin{array}{c}\text { Controls }=22.13(2.90) \\
\text { Dyslexics }=21.67(2.39)\end{array}$ & 0.199 & $p=.659$ \\
\hline $\begin{array}{l}\text { 4 Cells Highlighted } \\
\text { Updating Condition }\end{array}$ & $\begin{array}{c}\text { Controls }=20.31(3.66) \\
\text { Dyslexics }=17.58(4.68)\end{array}$ & 3.002 & $p=.700$ \\
\hline $\begin{array}{l}\text { 6 Cells Highlighted } \\
\text { Updating Condition }\end{array}$ & $\begin{array}{c}\text { Controls }=14.69(3.42) \\
\text { Dyslexics }=14.08(4.80)\end{array}$ & 0.152 & $p=.578$ \\
\hline $\begin{array}{l}\text { U Cells Highlighted } \\
\text { Updating Condition }\end{array}$ & $\begin{array}{c}\text { Controls }=14.81(4.02) \\
\text { Dyslexics }=15.67(3.89)\end{array}$ & 6.924 & $p=.014$ \\
\hline Updating Condition & Controls $=16.56(4.40)$ & & $p$ \\
\hline
\end{tabular}

Serial position was found to have a significant effect on performance, $F(3,78)=73.68, p<$ 0.001 , with more recently presented positions being remembered more accurately by both groups. Figure 4 displays the serial position data for each of the dynamic and updating conditions of the task. The repeated measures MANOVA showed there to be no significant interaction between group and serial position, $F<1$. A significant updating $\mathrm{x}$ serial position interaction was uncovered, $F$ (9, $234)=9.57, p<0.001$. The position of fewer of the least recently presented cells was correctly recalled under higher memory load conditions. There was no indication of a significant three-way interaction between group, updating, and serial position, $F(9,234)=1.15, p=0.326$.

The group $\mathrm{x}$ updating interaction, which was centred on the maximum updates condition (whilst the dyslexic group showed some difficulties when the fewest updates were required, this proved not to be significant statistically), warranted further investigation. Univariate F-tests with (1, 27) D.F. showed that the recall of the dyslexic and control groups differed significantly on the least recently presented position, $F=13.52 ; p<0.01$. The dyslexics recalled fewer positions correctly of the first cell that they were required to recall. Figure 4 would seem to suggest that the dyslexics also have some problems in recalling the second least recently presented cell, although this fell short of statistical significance, $F=2.40, p=0.132$. There were no significant differences in recall of the two most recently highlighted cells (Cell 3: $F<1$; Cell 4: $F<1$ ). 
Figure 4: Graphs showing mean recall scores (maximum 6) of the control and dyslexic groups on each of the dynamic and updating conditions of the pattern memory task. Means are given for each serial position $\left(1^{\text {st }}=\right.$ least recently presented cell, $4^{\text {th }}=$ most recently presented).

4 Cells Highlighted: Dynamic Condition.

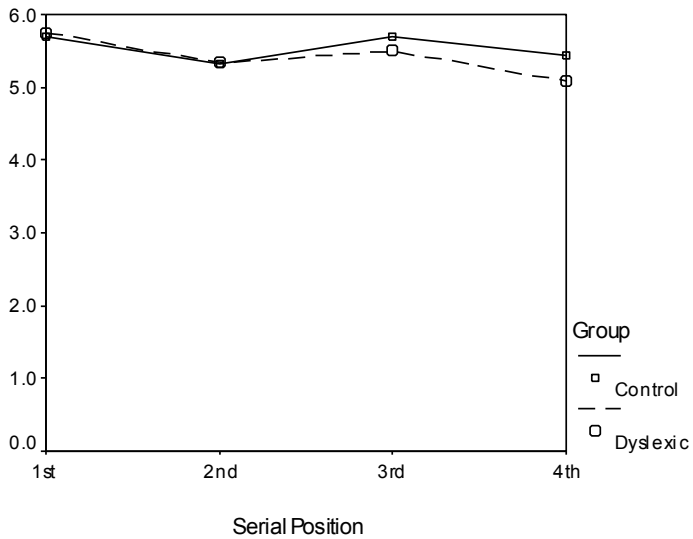

6 Cells Highlighted Updating Condition.

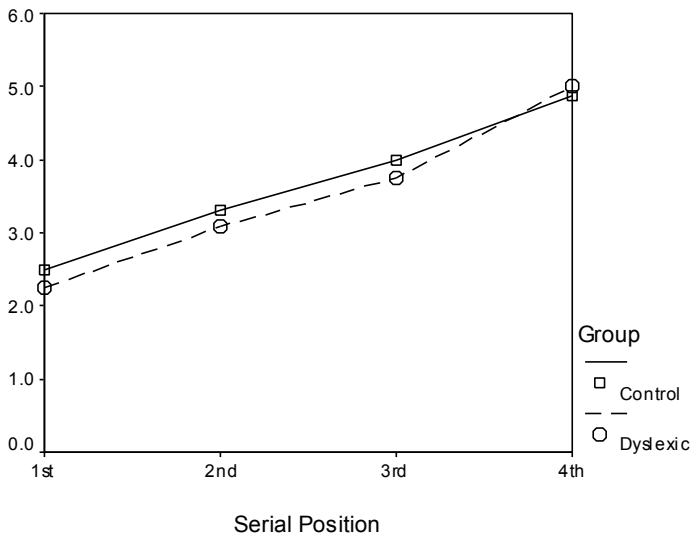

10 Cells Highlighted: Updating Condition.

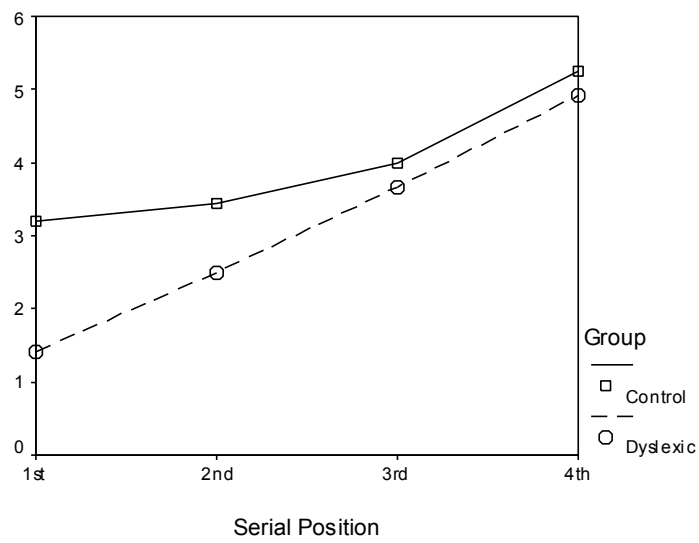

4 Cells Highlighted: Updating Condition.

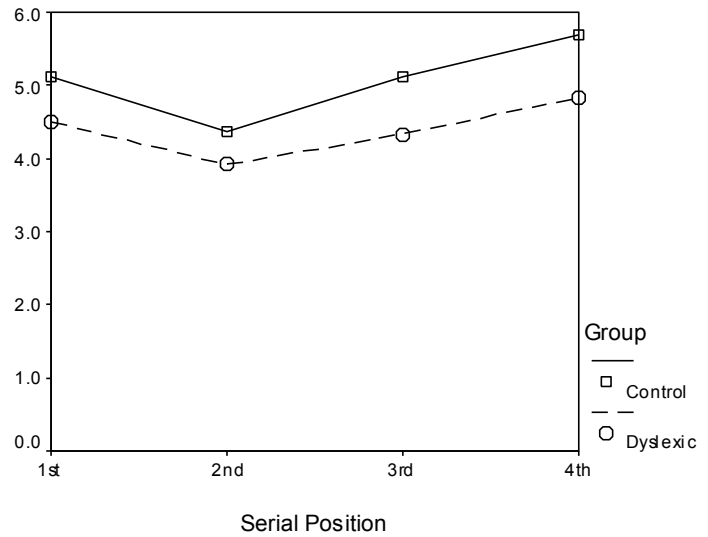

8 Cells Highlighted: Updating Condition.

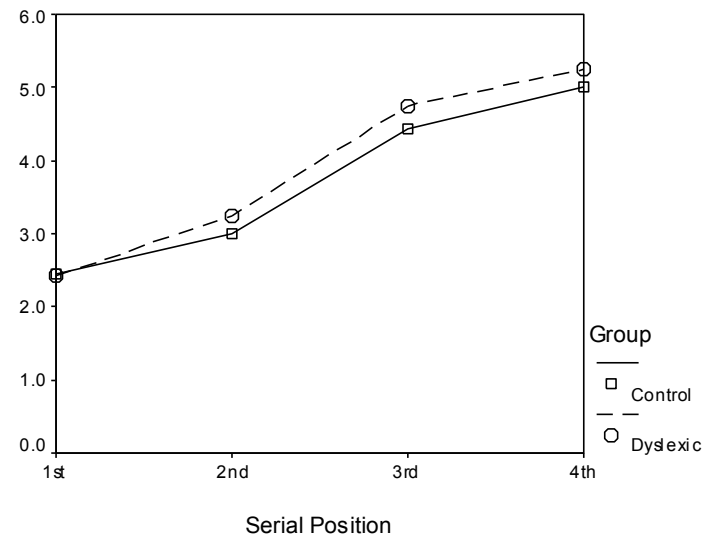




\section{DISCUSSION.}

Adult dyslexics do not seem to differ significantly from non-dyslexics in their ability to recall static or dynamic presentations of spatial information. It would appear also that, overall, students with dyslexia perform no worse than controls on the updating task. For both groups complexity (the number of updating operations required) and serial position of pattern elements were found to influence recall. A strong serial position effect was uncovered. On all conditions other than the least complex, recall of later items was better than for earlier positions. The significant difference in recall between performance on the dynamic version and on the updating condition requiring fewest updates indicated that, for both groups, the uncertainty associated with the updating conditions had an effect on performance, even when only 4 cells were highlighted sequentially within the matrix. Both of these findings are consistent with the findings of Fisk and Sharp (1999), who argue that, under conditions of uncertainty, updating appears to begin after the first two cells are highlighted. They conclude that, even at the simplest level, performance on the updating task is impaired relative to performance on the dynamic version.

On the dynamic memory condition, there was no significant group-related difference. This finding is similar to that of Gould and Glencross (1990), who found no evidence of a serial order memory deficit beyond the phonological domain in dyslexia and, more generally, replicates the findings of other studies on static memory in uncovering no significant differences between dyslexics and non-dyslexics. Both dyslexic and control participants performed at a high level of accuracy. This result is consistent with the phonological deficit hypothesis, since the task is essentially non-verbal. However, automaticity deficit theories of dyslexia would also predict no difference on this condition, since task demands are not sufficiently taxing to uncover impairments. In fact, the pattern of performance is similar to that reported in the phonological domain, after controlling for group differences in articulation rate (Nicolson, Fawcett, \& Baddeley, 1994; Hulme et al., 1995).

At first sight, it does not appear as though there are significant differences even under updating conditions. However, more sensitive analyses show that significant differences are elicited as the task becomes harder. The performance of the two groups was similar under the conditions with lower cognitive loads on the updating conditions. Inspection of the group $\mathrm{x}$ updating interaction provided some interesting, and unique, results. Whilst the two groups performed at comparable levels on the lower levels of the task, a significant group difference emerged when task demands were at their most taxing. On the maximum updates level, the dyslexics recalled fewer positions correctly overall than the controls. The significant effect of group was centred on the initial two positions to be recalled. With this high cognitive load, the performance of students with dyslexia was characterised by more rapid forgetting of the first two items, whilst recall of the final two cell positions was not significantly different from that of the non-dyslexic participants. It can be seen that the increase in cognitive load produces a classic resource effect. This could be interpreted in terms of automatisation deficits in basic processes in the central executive (such as shuffling material around central systems) or in terms of a central executive impairment (a lack of efficiency which may arise from a deficit in its constituent basic processes).

Since no differences were found on either the static or dynamic tasks or on the updating conditions with a lower cognitive load, those on the maximum updates condition could potentially be the result of an impairment in a more central system than that demanded by static recall, and this 
system appears to be affected by the load contributed by the updating requirements. This is a novel finding and cannot be explained by a purely phonological theory of dyslexia.

Although Morris (1987) argues that the use of a matrix may allow verbal recoding using grid references, the use of a verbal recoding strategy on this task seems unlikely, given the short display time for each stimulus and unsolicited anecdotal reports that suggested that participants were using mental representations of the matrices to aid recall. Moreover, Pickering et al. (2001) argue that the verbal labelling of a dynamic sequence could be time-consuming, complex, and less likely to be of use in its recall. In any case, Morris and Jones (1990) maintain that the updating component of their dynamic memory task is not reliant on the phonological system and it is this aspect of the present task that has been shown to be impaired in the dyslexic group.

That the group difference emerged in the present experiment only under the most taxing condition is in line with the hypothesis of Nicolson and Fawcett (1990), who found that dyslexics were able to hide their impairments on a range of tasks by a process of conscious compensation. When complexity (as represented by the number of updates required) was increased in the present study, performance declined significantly, differentiating dyslexics from controls. The allocation of extra resources to the task at hand is postulated to be a function of the central executive or supervisory attentional system (Norman \& Shallice, 1986). Since, by adulthood, the dyslexic has managed to compensate for many of the difficulties associated with the condition (and, presumably, the high-achieving dyslexics employed in this study have managed this better than most), this may account for the group difference being apparent only on the most complex level of the task. Swanson, Ashbaker, and Lee (1996) conclude that high processing demands lead to deficits on both verbal and visuo-spatial working memory measures in individuals with reading disability. This argues for a deficit in executive functioning and is supported by Swanson and Sachse-Lee (2001), who found that performance was equivalent on verbal and visuo-spatial working memory after matching their participants on executive processing ability.

\section{GENERAL DISCUSSION.}

The results of Experiment 1 have provided further evidence for the continuing impact of phonological working memory problems into adulthood in dyslexia, with impairments being evident on the short-term verbal memory tasks and the letter updating task. The problems would appear to surround the phonological loop and serial order memory. However, it has been stated already how difficult it is to separate phonological processing from working memory and that the participants appeared to make use of a recency-based strategy, thereby reducing its effectiveness as a measure of the central executive. As a consequence, visuo-spatial working memory was also investigated, being an under-explored area in dyslexia research.

Experiment 2 has shown that, under conditions of high task load, adult dyslexic students show impairments on complex visuo-spatial working memory span tasks. On the basis of the results of the static and dynamic spatial conditions and the lower levels of the updating task, it would seem that students with dyslexia do not display a general deficit in spatial memory. It is only when conditions are at their most taxing that a significant difference emerges between dyslexics and controls on the task, with the dyslexic group having problems maintaining information in working memory. There is, therefore, an important dissociation in the visuo-spatial working memory of dyslexics, with deficits only becoming apparent under the most taxing of updating conditions. 
If laboratory tests are not sufficiently demanding and do not reflect important aspects of working memory performance in everyday life (e.g. Smith-Spark, Fawcett, Nicolson, \& Fisk, In press), then it is not particularly surprising that major differences between dyslexics and nondyslexics have not been uncovered in central executive functioning. Further support for this argument is provided by the ability of dyslexics to mask their deficits under all but the most demanding conditions, by a process of "conscious compensation" (Nicolson \& Fawcett, 1990) in which spare attentional resources are allocated to the performance of a task. It is only when the demands (such as carrying out concurrent tasks) outweigh attentional resources that dyslexic deficits become apparent.

Manuscript submitted October 232001. Manuscript accepted January 72003. 


\section{REFERENCES.}

Ackerman, P.T., \& Dykman, R.A. (1993). Phonological processes, confrontational naming, and immediate memory in dyslexics. Journal of Learning Disabilities, 26(9), 597-609.

Avons, S.E., \& Hanna, C. (1995). The memory-span deficit in children with specific reading disability: is speech rate responsible? British Journal of Developmental Psychology, 13, 303-311.

Baddeley, A.D. (1986). Working Memory. Oxford, UK: Clarendon Press.

Baddeley, A.D., \& Hitch, G. J. (1993). The recency effect: implicit learning with explicit retrieval? Memory and Cognition, 21, 146-155.

Badian, N.A. (1984). Reading Disability as an epidemiological context: incidence and environmental correlates. Journal of Learning Disabilities, 17, 129-136.

Brachacki, G.W.Z., Fawcett, A.J., \& Nicolson, R.I. (1994). Adults with dyslexia have a deficit in voice recognition. Perceptual and Motor Skills, 78 (1), 304-306.

Brunswick, N. McCrory, E., Price, C.J., Frith, C.D., \& Frith, U. (1999). Explicit and implicit processing of words and pseudowords by adult developmental dyslexics. A search for Wernicke's Wortschatz? Brain, 122, 1901-1917.

Bruyer, R., \& Scailquin, J.-C. (1998). The visuospatial sketchpad for mental images: testing the multicomponent model of working memory. Acta Psychologica, 98, 17-36.

Cohen, R.L., Netley, C., \& Clarke, M.A. (1984). On the generality of the short-term memory/reading ability relationship. Journal of Reading Disabilities, 17, 218-221.

Finucci, J.M., Guthrie, J.T., Childs, A.L., Abbey, H., \& Childs, R. (1976). The genetics of specific reading disability. Annals of Human Genetics, 50, 1-23.

Fisk, J.E., \& Sharp, C.A. (1999). The role of the central executive in visuo-spatial memory updating. Paper presented at Cognitive Psychology Section, British Psychological Society, XVI Annual Conference, University of York, September 1999.

Fisk, J.E., \& Warr, P.B. (1996). Age and working memory: The role of perceptual speed, the central executive, and the phonological loop. Psychology and Aging, 11, 316-323.

Frith, U. (1985). Beneath the surface of developmental dyslexia. In K.E. Patterson, J.C. Marshall \& M. Coltheart (Eds.), Surface Dyslexia. London, UK: Routledge and Kegan Paul.

Gathercole, S.E. (1994). The children's test of nonword repetition: A test of phonological working memory. Memory, 2(2), 103-127.

Gathercole, S.E., Willis, C., Emslie, H., \& Baddeley, A.D. (1991). The influences of number of syllables and wordlikeness on children's repetition of nonwords. Applied Psycholinguistics, $\underline{12}, 349-367$.

Gould, J.H., \& Glencross, D.J. (1990). Do children with a specific reading-disability have a general serial ordering deficit? Neuropsychologia, 28(3), 271-278.

Hulme, C., Roodenrys, S., Brown, G., \& Mercer, R. (1995). The role of long-term memory mechanisms in memory span. British Journal of Psychology, 86(4), 527-536.

Jorm, A.F. (1983). Specific reading retardation and working memory: A review. British Journal of Psychology, 74, 311-342.

Logie, R.H., \& Pearson, D.G. (1997). The inner eye and the inner scribe of visuo-spatial working memory: evidence from developmental fractionation. European Journal of Cognitive Psychology, 9(3), 241-257.

McDougall, S.J.P., \& Donohoe, R. (2002). Reading ability and memory span: Long-term 
memory contributions to span for good and poor readers. Reading and Writing: An Interdisciplinary Journal, 15, 359-387.

McLoughlin, D., Fitzgibbon, G., \& Young, V. (1994). Adult Dyslexia: Assessment, Counselling and Training. London, UK: Whurr.

Miles, T.R. (1983). Dyslexia: The Pattern of Difficulties. London, UK: Priory Press.

Morris, N. (1987). Exploring the visuo-spatial scratch pad. Quarterly Journal of Experimental Psychology, 39(A), 409-430.

Morris, N., \& Jones, D.M. (1990). Memory updating in working memory: The role of the central executive. British Journal of Psychology, 81, 111-121.

Nicolson, R.I., \& Fawcett, A.J. (1990). Automaticity: a new framework for dyslexia research. Cognition, 35, 159-182.

Nicolson, R.I., \& Fawcett, A.J. (1994). Comparison of deficits in cognitive and motor skills among children with dyslexia. Annals of Dyslexia, 44, 147-164.

Nicolson, R.I., and Fawcett, A.J. (1997). Development of objective procedures for screening and assessment of dyslexic students in higher education. Journal of Research in Reading, 20(1), 77-83.

Nicolson, R.I., Fawcett, A.J., \& Baddeley (1994). Working memory and dyslexia. Internal Report. Learning Research Group. Department of Psychology, University of Sheffield.

Nicolson, R.I., Fawcett, A.J., \& Dean, P. (1995). Time estimation deficits in Developmental Dyslexia: Evidence of Cerebellar Involvement. Proceedings of the Royal Society of London, Series B: Biological Sciences, Vol. 259 (No. 1354), 43-47.

Nicolson, R.I., Fawcett, A.J., \& Dean, P. (2001). Developmental dyslexia: the cerebellar deficit hypothesis. Trends in Neurosciences, 24(9), 508-511.

Norman, D.A., \& Shallice, T. (1986). Attention to Action: Willed and Automatic Control of Behaviour. In R.J. Davidson, G.E. Schwartz, \& D. Shapiro (Eds.), Consciousness and SelfRegulation: Advances in Research and Theory, (Vol.4, pp. 1-18). New York: Plenum Press.

Olson, R., \& Datta, H. (2002). Visual-temporal processing in reading-disabled and normal twins. Reading and Writing: An Interdisciplinary Journal, 15, 127-149.

Pennington, Cardoso-Martins, Green, \& Lefly, (2001). Comparing the phonological and double deficit hypotheses for developmental dyslexia. Reading and Writing: An Interdisciplinary Journal, 14, 707-755.

Pickering, S.J. (2001). Cognitive approaches to the fractionation of visuo-spatial working memory. Cortex, 37, 457-473.

Pickering, S.J., Gathercole, S.E., Hall, M., \& Lloyd, S.A. (2001). Development of memory for pattern and path: further evidence for the fractionation of visuo-spatial memory. Quarterly Journal of Experimental Psychology, 54A (2), 397-420.

Plaza, M., Cohen, H., \& Chevrie-Muller, C. (2002). Oral language deficits in dyslexic children: weaknesses in working memory and verbal planning. Brain \& Cognition, $\underline{48(2-3)}$, 505-512.

Roodenrys, S., \& Stokes, J. (2001). Serial recall and nonword repetition in reading disabled children. Reading and Writing: An Interdisciplinary Journal, 14, 379-394.

Salthouse, T.A. (1992). Influence of information processing speed on adult age differences in working memory. Acta Psychologica, 79, 155-170.

Salthouse, T.A., Kausler, D.H., \& Saults, J. S. (1988a). Investigation of student status, background variables, and feasibility of standard tasks in cognitive aging research. Psychology and Aging, 3(1), 29-37.

Salthouse, T.A., Kausler, D.H., \& Saults, J. S. (1988b). Utilization of path-analytic 
procedures to investigate the role of processing resources in cognitive aging. Psychology and Aging, 3(2), 158-166.

Smith-Spark, J.H. (2000). Memory in Adult Dyslexics: An Exploration of the Working Memory System. Unpublished PhD thesis, University of Sheffield, UK.

Smith-Spark, J.H., Fawcett, A.J., Nicolson, R.I., \& Fisk, J.E. (In press). Dyslexic students have more everyday cognitive lapses. Accepted by Memory.

Snowling, M. (1987). Dyslexia: A cognitive developmental perspective. Oxford, UK: Blackwell.

Snowling, M.J., Chiat, S., \& Hulme, C. (1991). Words, nonwords, and phonological processes: Some comments on Gathercole, Willis, Emslie, and Baddeley. Applied Psycholinguistics, 12, 369-373.

Stanovich, K.E. (1988). The right and wrong places to look for the cognitive locus of reading disability. Annals of Dyslexia, $\underline{38}, 154-177$.

Swanson, H.L. (1993). Working memory in learning disability subgroups. Journal of Experimental Child Psychology, 56, 87-114.

Swanson, H.L. (1999). Reading comprehension and working memory in learning-disabled readers: is the phonological loop more important than the executive system? Journal of Experimental Child Psychology, 72, 1-31.

Swanson, H.L., Ashbaker, M.H., \& Lee, C. (1996). Learning-disabled readers' working memory as a function of processing demands. Journal of Experimental Child Psychology, 61, 242-275.

Swanson, H.L., \& Sachse-Lee, C. (2001). A subgroup analysis of working memory in children with reading disabilities: domain-general or domain-specific deficiency. Journal of Learning Disabilities, 34(3), 249-263.

Talcott, J. B., Hansen, P. C., Willis-Owen, C., McKinnell, I. W., Richardson. A. F., \& Stein, J. F. (1998). Visual magnocellular impairment in adult developmental dyslexics. Neuroopthalmology, 20, 187-201.

Vecchi, T., \& Cornoldi, C. (1999). Passive storage and active manipulation in visuospatial memory: further evidence from the study of age differences. European Journal of Cognitive Psychology, 11 (3), 391-406.

Vellutino, F.R. (1979). Dyslexia: Theory and Research. Cambridge, MA: MIT Press.

Wechsler, D. (1986a). The Wechsler Adult Intelligence Scale- Revised (UK Edition). Sidcup, Kent: The Psychological Corporation.

Wechsler, D. (1986b). The Wechsler Objective Reading Dimension. Sidcup, Kent: The Psychological Corporation.

Wilson, A.M., \& Lesaux, N.K. (2001). Persistence of phonological processing deficits in college students with dyslexia who have age-appropriate reading skills. Journal of Learning Disabilities, 34(5), 394-400.

Wimmer, H. (1993). Characteristics of developmental dyslexia in a regular writing system. Applied Psycholinguistics, 14 (1), 1-33.

Winner, E., von Karolyi, C., Malinsky, D., French, L., Seliger, C., Ross, E., \& Weber, C. (2001). Dyslexia and visual-spatial talents: compensation vs deficit model. $\underline{\text { Brain \& }}$ Language, 76, 81-110.

Wolf, M., \& Bowers, P.G. (1999). The double-deficit hypothesis for the developmental dyslexias. Journal of Educational Psychology, 91, 415-438. 
APPENDIX I: The performance of the dyslexic group on the ADI measures. WAIS ACID subtest scores falling short of the average non-ACID scores by three or more points are indicated by an asterisk. See Nicolson and Fawcett (1997) for details of the other cut-off scores. ** Data collected but not available at time of testing.

\begin{tabular}{|c|c|c|c|c|c|c|}
\hline $\begin{array}{l}\text { Participant } \\
\text { Number }\end{array}$ & $\begin{array}{l}\text { Previous } \\
\text { Diagnosis }\end{array}$ & $\begin{array}{l}\text { BAS/Word } \\
\text { Spelling } \\
\text { Scale }\end{array}$ & Nonsense Word Passage & WAIS Profile & $\begin{array}{l}\text { Total } \\
\text { ADI } \\
\text { score }\end{array}$ & $\mathbf{I Q}$ \\
\hline 1 & $\begin{array}{l}\text { No } \\
\text { ADI }=0\end{array}$ & $\begin{array}{l}>17 \text { years } \\
\mathrm{ADI}=0\end{array}$ & $\begin{array}{l}\text { Error score }=9 \\
\text { Completion Time }=91 \mathrm{~s} \\
\text { ADI }=1\end{array}$ & $\begin{array}{l}\text { Mean WAIS (Non-ACID) }=12.0 \\
\mathrm{~A}=9^{*}, \mathrm{DSym}=8^{*}, \mathrm{DSpa}=10, \mathrm{I}=13 \\
\mathrm{ADI}=1\end{array}$ & 2.0 & 120 \\
\hline 2 & $\begin{array}{l}\text { Yes } \\
\text { ADI }=1\end{array}$ & $\begin{array}{l}16.3 \text { years } \\
\mathrm{ADI}=0.5\end{array}$ & $\begin{array}{l}\text { Error score }=16 \\
\text { Completion time }=74 \mathrm{~s} \\
\mathrm{ADI}=1\end{array}$ & $\begin{array}{l}\text { Mean WAIS }(\text { Non-ACID })=12.29 \\
A=13, \text { DSym }=9 *, D S p a=3^{*}, I=12 \\
\mathrm{ADI}=1\end{array}$ & 3.5 & 106 \\
\hline 3 & $\begin{array}{l}\text { Yes } \\
\text { ADI }=1\end{array}$ & $\begin{array}{l}9.3 \text { years } \\
\text { ADI }=1\end{array}$ & $\begin{array}{l}\text { Error score }=22 \\
\text { Completion time }=115 \mathrm{~s} \\
\mathrm{ADI}=1\end{array}$ & $\begin{array}{l}\text { Mean WAIS (Non-ACID) }=10.86 \\
\mathrm{~A}=7^{*}, \mathrm{DSym}=4^{*}, \mathrm{DSpa}=4 *, \mathrm{I}=9 \\
\mathrm{ADI}=1\end{array}$ & 4.0 & 99 \\
\hline 4 & $\begin{array}{l}\text { No } \\
\mathrm{ADI}=0\end{array}$ & $\begin{array}{l}14.9 \text { years } \\
\mathrm{ADI}=1\end{array}$ & $\begin{array}{l}\text { Error score }=6 \\
\text { Completion time }=71 \mathrm{~s} \\
\mathrm{ADI}=0.5\end{array}$ & $\begin{array}{l}\text { Mean WAIS }(\text { Non-ACID })=13.29 \\
\mathrm{~A}=13, \mathrm{DSym}=8^{*}, \mathrm{DSpa}=10, \mathrm{I}=9^{*} \\
\mathrm{ADI}=1\end{array}$ & 2.5 & 117 \\
\hline 5 & $\begin{array}{l}\text { No } \\
\text { ADI }=0\end{array}$ & $\begin{array}{l}>17 \text { years } \\
\text { ADI }=0\end{array}$ & $\begin{array}{l}\text { Error score }=10 \\
\text { Completion time }=73 \mathrm{~s} \\
\mathrm{ADI}=1\end{array}$ & $\begin{array}{l}\text { Mean WAIS (Non-ACID) }=12.6 \\
\mathrm{~A}=8^{*}, \mathrm{DSym}=7^{*}, \mathrm{DSpa}=8^{*}, \mathrm{I}=13 \\
\mathrm{ADI}=1\end{array}$ & 2.0 & 109 \\
\hline 6 & $\begin{array}{l}\text { Yes } \\
\text { ADI }=1\end{array}$ & $\begin{array}{l}11 \text { years } \\
\mathrm{ADI}=1\end{array}$ & $\begin{array}{l}\text { Error score }=11 \\
\text { Completion time }=93 \mathrm{~s} \\
\mathrm{ADI}=1\end{array}$ & $\begin{array}{l}\text { Mean WAIS }(\text { Non-ACID })=11.0 \\
\mathrm{~A}=6^{*}, \mathrm{DSym}=10, \mathrm{DSpa}=8^{*}, \mathrm{I}=8^{*} \\
\mathrm{ADI}=1\end{array}$ & 4 & 97 \\
\hline
\end{tabular}


APPENDIX 1 (Continued).

\begin{tabular}{|c|c|c|c|c|c|c|}
\hline $\begin{array}{l}\text { Participant } \\
\text { Number }\end{array}$ & $\begin{array}{l}\text { Previous } \\
\text { Diagnosis }\end{array}$ & $\begin{array}{l}\text { BAS/Word } \\
\text { Spelling } \\
\text { Scale } \\
\end{array}$ & Nonsense Word Passage & WAIS Profile & $\begin{array}{l}\text { Total } \\
\text { ADI } \\
\text { score }\end{array}$ & IQ \\
\hline 7 & $\begin{array}{l}\text { No } \\
\text { ADI }=0\end{array}$ & $\begin{array}{l}13.3 \text { years } \\
\text { ADI }=1\end{array}$ & $\begin{array}{l}\text { Error score }=18 \\
\text { Completion time }=97 \mathrm{~s} \\
\mathrm{ADI}=1\end{array}$ & $\begin{array}{l}\text { Mean WAIS }(\text { Non-ACID })=9.7 \\
A=6^{*}, \text { DSym }=12, \text { DSpa }=6^{*}, I=6^{*} \\
\text { ADI }=1\end{array}$ & 3.0 & 108 \\
\hline 8 & $\begin{array}{l}\text { No } \\
\text { ADI }=0\end{array}$ & $\begin{array}{l}11.9 \text { years } \\
\text { ADI }=1\end{array}$ & $\begin{array}{l}\text { Error score }=11 \\
\text { Completion time }=100 \mathrm{~s} \\
\text { ADI }=1\end{array}$ & $\begin{array}{l}\text { Mean WAIS }(\text { Non-ACID })=12.9 \\
\mathrm{~A}=11, \mathrm{DSym}=8^{*}, \mathrm{DSpa}=9^{*}, \mathrm{I}=10 \\
\mathrm{ADI}=1\end{array}$ & 3.5 & 106 \\
\hline 9 & $\begin{array}{l}\text { Yes } \\
\text { ADI }=1\end{array}$ & $\begin{array}{l}11.0 \text { years } \\
\text { ADI }=1\end{array}$ & $\begin{array}{l}\text { Error score }=19 \\
\text { Completion time }=93 \mathrm{~s} \\
\mathrm{ADI}=1\end{array}$ & $\begin{array}{l}\text { Mean WAIS }(\text { Non-ACID) }=10.71 \\
\mathrm{A}=10, \mathrm{DSym}=6^{*}, \mathrm{DSpa}=8, \mathrm{I}=10 \\
\mathrm{ADI}=0.5\end{array}$ & 3.5 & 97 \\
\hline 10 & N/A ** & $\mathrm{N} / \mathrm{A} * *$ & N/A ** & N/A ** & 3.0 & 104 \\
\hline 11 & N/A ** & N/A ** & $\mathrm{N} / \mathrm{A} * *$ & N/A ** & 2.5 & 131 \\
\hline 12 & N/A ** & N/A ** & $\mathrm{N} / \mathrm{A} * *$ & N/A ** & 3.0 & 118 \\
\hline
\end{tabular}

Key: $\mathrm{A}=$ Arithmetic, DSym $=$ Digit Symbol, DSpa $=$ Digit Span, I = Information. 